logical difficulties of validating science, "there is nearly universal human consensus concerning certain aspects of of the material domain". He leaves open the question "whether the categorial framework of everyday realism is the only possible scheme for describing and understanding nature in its physical aspects". He is content to leave it like this, but is not optimistic that "psychology and neurophysiology can arrive at a better understanding than, say, the ancient art of introspection".

Here I should disagree with him. Although he has taken the trouble to study these biological subjects seriously, I do not think he appreciates the speed with which they are approaching the capacity to achieve consensual communication that is useful even if not completely unambiguous. It is not too wild a statement to say that we are within sight of a 'complete' science of biology with principles that cover the origin, evolution and present operations of living things. It is true that the extension of this to include Man raises special difficulties. He rightly dwells in his concluding chapters on the difficulties of precise definition of such concepts as "intelligence", "caste", "peasant" or "psychosis". In fact "we do not have a taxonomic framework for human behaviour, individual or social, in which the categories are both meaningful and distinct". True enough, and we all deplore the weakness of sociology. The difficulties introduced by hidden variables will of course always make the study of complex systems more difficult than that of simple ones. If the aim was to find some logically perfect science of man then indeed $I$ should be pessimistic. But Ziman has taken pains to show us that the whole of science is simply an empirical, useful, predictive enterprise, characteristic of modern Homo sapiens. The life sciences are a part of this enterprise that is at present developing very rapidly, and I believe that his careful attention to them has already been very helpful and will be even more so in the future.

J. Z. Young is Emeritus Professor of Anatomy at University College, London, UK.

indeterminancy of natural language propositions, he will reject this thesis. Only in this way, argues Professor Dummett, can philosophy aspire to a 'scientific' status and emerge from a 'scandalous' historical situation in which interminable effort and ingenuity "appears to engender nothing but unending disagreements."

Dummett's own papers represent this programme. They are closely-argued, rigorous and subtle steps towards a 'theory of meaning' capable of generating and testing a better understanding of 'truth', of the conditions under which a sentence may be correctly asserted, about whether the reality that renders key classes of empirical statements true or false can be shown to be fully determinate. These concerns are closely linked to a series of highly technical considerations (of special interest to the mathematician, to the mathematical logician but also, at several points, to the scientist in general) on the conflict between realists and intutionists in mathematics, on the philosophical reach of Gödel's theorem and on the justification of deduction. Physicists, familiar with notions of time-reversal, will find much to instruct and delight them in two essays on "Can an Effect Precede Its Cause?" and "Bringing About the Past". Professor Dummett is a master of logic and of analytical exposition, and where one fails to agree-has he allowed for the characteristic and shrewd pragmatism which underlies Quine's thesis on the indeterminancy of translations between languages, a thesis which cannot be

\section{Biology of Seaweeds}

Levels of Organization

A. R. O. Chapman

By dealing in turn with cells, whole organisms, populations, and

communities, this skilfully designed, clearly written text fills the need felt by many phycology instructors for an organizational approach for their courses on algal biology in place of the traditional texts that attempt to review the entire field systematically or by functional organization. The book focuses mainly on seaweed algae and emphasizes ecological considerations to point out the unifying trends and

concepts that are essential for a

student's thorough understanding of the subject.

Biology of Seaweeds is a stimulating and precisely targeted textbook for intermediate and advanced students of phycology. It reflects throughout Dr. Chapman's extensive experience as a teacher and his expert knowledge of algal biology.

Paper £5.95 Publication May

\section{Adaptation to Thermal Environment: \\ Man and his Productive Animals \\ Lawrence E. Mount \\ Contemporary Biology Series}

This book deals with the principles underlying the heat exchanges that take place between an animal and its thermal environment, and with the application of these principles to man and to those animals that are of agricultural

importance. The text is in two parts: the first part consists of six chapters dealing with the basic considerations that apply to the relations between an animal and its thermal environment.

The second part contains accounts of the different species. May

Boards $£ 16$ Paper $£ 7.50$ Publication Soon to be available as a Student Paperback:

\section{Plant Virology: The Principles}

\section{Adrian Gibbs and Bryan Harrison}

This modern exposition of plant virology aims to describe the framework of knowledge about plant viruses and to outline the methods used in obtaining this knowledge. The numerous illustrations include superb electron micrographs - many of them original and other photographs as well as numerous line diagrams. Thus the framework of the subject is provided and much practical information on how plant viruses can be studied is given.

Paper $£ 9.75$ Publication June

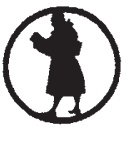

Edward Arnold 41 Bedford Square, London WC1B 3DQ determination of such propositions. And though, again, aware of the teasing finesse of Quine's thesis on the 
simply reduced to an intralinguistic model? - one does so at one's peril.

Professor Dummett's conviction that "we have now reached a situation" where what he postulates to be the fundamental philosophic problem, the theory of meaning, "can be resolved to the satisfaction of everyone" and, above all, be successfully resolved "within a finite time", is one of radical innocence. It may have at its core a certain personal element-even the most abstract, analytical thought has a living presence and agent behind it. There are tantalising hints that even in respect of mathematics, Dummett's provisional realism has a theistic basis or that 'metaphysics' is for him far from being nonsense if a systematic theory of meaning underlies it. Indeed, says, Dummett, "If I have made any worthwhile contribution to philosophy, I think it must lie in having raised this issue in these terms." The implications are very wide and of the greatest importance.

It is the more regrettable that the two papers in which Dummett deals with the history of 'linguistic philosophies' in this country, and with the attacks (however technically inept) made on the narrowness, on the purely technical scholasticism of these philosophies, should decline to engage the real issue. This issue is not whether Strawson has been misinterpreted or whether Ayer has seen the importance of Frege's logic. It is whether or not the concerns which Professor Dummett so brilliantly pursues are central, are adequate to the concept of philosophy in society and the lives of individuals. The charge, and Dummett does not answer it, is simply this: Oxbridge linguistic logic has trivialised the enterprise of the philosopher. It has sought to eliminate ethics, aesthetics, metaphysics in the very sense in which Dummett invokes it. It has chosen to ignore, in Owen Chadwick's remarkable phrase, the extent to which, since the 1930s, "the agonies and passions of mankind started to enter and complicate the philosophies." The challenge is a real one. No-one would meet it better than Professor Dummett himself.

George Steiner is Professor of English and Comparative Literature at the University of Geneva, Switzerland.

\section{Panorama of modern neurobiology}

\section{Leslie Iversen}

Molecular Neurobiology of the Mammalian Brain. By P. L. McGeer, Sir John C. Eccles and E. G. McGeer. Pp. 644. (Plenum: New York and London, 1978.)

THIS substantial volume represents the results of an ambitious undertaking by two biochemists who have pioneered the application of biochemical approaches to studies of chemical neurotransmitters in the brain, and one of the most eminent neurophysiologists of our time. An ambitious undertaking because they seek to bring together in one volume virtually all of the achievements of modern cellular neurobiology and to show how far this basic information can be used to explain the integrative functions of the mammalian brain. This is promising stuff, and the reader is further encouraged by the authors' principle that they should provide not merely a bare factual account of present knowledge, but attempt to give some outline of the key events in the historical development of such knowledge from the interplay of hypothesis and experiment. We may even hope that the basic cellular data will and in the central nervous system (CNS). A series of fairly detailed chapters summarise current knowledge of the specialised biochemical properties associated with neurones using acetylcholine, amino acids, catecholamines, or 5-hydroxytryptamine as transmitter, and others cover the new field of 'promising peptides' and various other putative CNS transmitters, accompanied in each case by a brief outline of the actions of drugs on neurotransmitter mechanisms.

The coverage of neurotransmitters is good and up to date, although more explanation and examples could have been given of ligand-binding techniques for the study of neurotransmitter receptors in CNS, a development which has had a major impact on neurochemical studies of such mechanisms in recent years. The undue emphasis given to acetylcholine and catecholamines (almost 100 pages) continues to reflect the inadequacy of our current knowledge of other CNS transmitters, rather than the true importance of the monoamines in CNS function.

A third section of some 200 pages gives a wide-ranging review of integrative aspects of brain function, from development and plasticity to motor control mechanisms, learning and memory, and perception, speech and consciousness. The aim is to refer back in this section to the basic properties of neurones described previously. This aim is sometimes successfully achieved: for example, in the description of the extrapyramidal motor control systems in basal ganglia, in which anatomical, physiological and neurotransmitter aspects are well integrated, with discussion of human basal ganglia disease, such as Parkinsonism and Huntington's Chorea and their treatment by drugs, neatly interspersed. On the other hand, the description of cerebellar function completely omits any mention of the neurotransmitters involved, despite referance in earlier sections to the important role of the putative amino acid transmitters, $\gamma$-aminobutyric acid and glutamate, in this region of the brain. An ambitious chapter on basic aspects of behaviour includes a description of central endocrine influences and the CNS actions of psychoactive drugs, together with a review of current neuropharmacological theories of mental illness. As complexity increases with each succeeding chapter it is inevitable that the book ends with a discussion of perception and consciousness, in which the dualist-interactionist hypothesis-described in more detail in the recent book by K. R. Popper and J. C. Eccles The Self and Its Brain (Springer: Berlin, 1977; for review, see Nature, 272, 770, 1978)-is restated. The reader is given plenty of advance warning of this conclusion: in discussing the ques- 